Review Article

\title{
Circadian Regulation of Hippocampal-Dependent Memory: Circuits, Synapses, and Molecular Mechanisms
}

\author{
Kaitlin H. Snider (D), Kyle A. Sullivan (D), and Karl Obrietan (D) \\ Department of Neuroscience, Ohio State University, Columbus, OH 43210, USA \\ Correspondence should be addressed to Kaitlin H. Snider; snider.283@buckeyemail.osu.edu \\ and Karl Obrietan; obrietan.1@osu.edu
}

Received 28 September 2017; Accepted 18 December 2017; Published 8 February 2018

Academic Editor: Karen Gamble

Copyright (C) 2018 Kaitlin H. Snider et al. This is an open access article distributed under the Creative Commons Attribution License, which permits unrestricted use, distribution, and reproduction in any medium, provided the original work is properly cited.

\begin{abstract}
Circadian modulation of learning and memory efficiency is an evolutionarily conserved phenomenon, occurring in organisms ranging from invertebrates to higher mammalian species, including humans. While the suprachiasmatic nucleus (SCN) of the hypothalamus functions as the master mammalian pacemaker, recent evidence suggests that forebrain regions, including the hippocampus, exhibit oscillatory capacity. This finding, as well as work on the cellular signaling events that underlie learning and memory, has opened promising new avenues of investigation into the precise cellular, molecular, and circuit-based mechanisms by which clock timing impacts plasticity and cognition. In this review, we examine the complex molecular relationship between clock timing and memory, with a focus on hippocampal-dependent tasks. We evaluate how the dysregulation of circadian timing, both at the level of the SCN and at the level of ancillary forebrain clocks, affects learning and memory. Further, we discuss experimentally validated intracellular signaling pathways (e.g., ERK/MAPK and GSK3 $\beta$ ) and potential cellular signaling mechanisms by which the clock affects learning and memory formation. Finally, we examine how long-term potentiation (LTP), a synaptic process critical to the establishment of several forms of memory, is regulated by clock-gated processes.
\end{abstract}

\section{Introduction}

Forty-five years ago, Davies et al. [1] first demonstrated that the efficiency of both learning and memory is modulated as a function of the time-of-day. Using a passive avoidance task (where animals learn to avoid a mild foot shock by remaining in the lighted side of a test chamber), they demonstrated that rats learned and remembered the task better during the day than during the night. In the decades since, numerous labs have confirmed that learning and memory are gated over the diurnal cycle [1-19]. Further, many of these diurnally regulated effects on learning and memory efficiency persist even when external time cues are eliminated $[4,12,17,18,20]$; thus this gating process is governed by inherent circadian timekeeping capacity. Circadian variation in memory is seen across phyla, from Aplysia [21] and fruit flies [22] to mice [4] and humans [23]. Furthermore, alterations in clock timing (whether resulting from jet lag $[24,25]$ or shift work $[26,27])$ cause cognitive deficits. Likewise, cognitive impairment and dysregulation of the circadian timing system are comorbid (and possibly interrelated) features of many neurodegenerative disorders [28, 29], including Alzheimer's [30, 31], Parkinson's [32-34], and Huntington's disease [35-37]. These findings suggest that inherent circadian timekeeping capacity has a profound influence on the cellular and systems-based circuitry that underlies memory formation. As such, a better understanding of the mechanisms by which the circadian clock modulates cognition has wideranging implications for human health, disease progression, and overall quality of life.

In this review, we focus on circadian modulation of hippocampal-dependent forms of learning and memory. To this end, our discussion will be focused on hippocampusdependent forms of spatial and contextual memory [38]. Importantly, both the circuits and many of the molecular 
TABLE 1: Hippocampus-dependent memory tasks regulated by time-of-day, sorted by memory process (WM: working memory; ITM: intermediate-term memory; LTM: long-term memory; Acq: acquisition; Ret: retrieval).

\begin{tabular}{|c|c|c|c|c|}
\hline Process & Assay & Phase (peak/nadir) & Model & Reference \\
\hline WM & Radial arm maze & Night (21/7) & Sprague-Dawley rats & Hauber and Bareiss [3] \\
\hline WM & Radial arm maze & Day $(2 / 14)$ & $\mathrm{C} 3 \mathrm{H} / \mathrm{HeN}$ mice & Rawashdeh et al. [55] \\
\hline WM & Spontaneous alternation & Night (19/7) & Siberian hamsters & Ruby et al. [10] \\
\hline WM & Sustained attention task & Night (16/4) & Sprague-Dawley rats & Gritton et al. [12] \\
\hline ITM & Novel object location & Night (20/8) & Wistar rats & Takahashi et al. [14] \\
\hline ITM & Novel object location & Night (16/4) & C57BL/6 mice & Snider et al. [20] \\
\hline ITM & Novel object recognition & Night (19/3) & Siberian hamsters & Ruby et al. [9] \\
\hline LTM & Alley maze & Night $(18 / 6)$ & C57BL/6 Ola mice & Hoffmann and Balschun [2] \\
\hline LTM & Contextual fear conditioning & Night (14/2) & C57BL/6J mice & Valentinuzzi et al. [19] \\
\hline LTM & Contextual fear conditioning & Day $(4 / 16)$ & C57BL/6 mice & Eckel-Mahan et al. [18] \\
\hline LTM (Ret) & Contextual fear conditioning & Day $(3 / 21)$ & $\mathrm{C} 57 \mathrm{BL} / 6 \mathrm{~J}$ and $\mathrm{C}-3 \mathrm{H}$ mice & Chaudhury and Colwell [4] \\
\hline LTM & Passive avoidance & Day $(6 / 18)$ & Sprague-Dawley rats & Davies et al. [1] \\
\hline LTM & Trace fear conditioning & Day $(6 / 18)$ & C57BL/6 mice & Wang et al. [5] \\
\hline LTM & Morris Water Maze & Night $(16 / 4)$ & Sprague-Dawley rats & Gritton et al. [12] \\
\hline LTM & Radial arm maze & Night $(21 / 7)$ & Sprague-Dawley rats & Hauber and Bareiss [3] \\
\hline $\operatorname{LTM}($ Acq) & Novel object recognition & Night $(16 / 4)$ & C57BL/6 mice & Shimizu et al. [42] \\
\hline
\end{tabular}

mechanisms that underlie spatial and contextual memory are well characterized [39-41], and as such, the effects of the clock timing system can be examined within a functionally relevant cellular context [20, 42-44]. Further, we will present an extensive overview of the existing hypotheses on the mechanisms by which circadian rhythms modulate memory efficiency, as well as comment on broader implications of these hypotheses. We will begin by briefly discussing several hippocampal forms of learning and memory, describing the assays used to examine these processes, and reviewing work that places these memory processes into a circadian context.

In rodent model systems, circadian modulation of a wide array of hippocampal-dependent memory processes has been reported (for a summary see Table 1). Notably, while the learning and memory assays discussed in this review require the hippocampus, the level of this hippocampal dependence varies from assay to assay. Some assays (e.g., novel object location) are almost exclusively dependent on the hippocampus [45], while others (contextual fear conditioning or novel object recognition) also involve additional brain regions such as the amygdala and perirhinal cortex, respectively [45-47]. Generally, memory processes can be divided by mechanism and time scale into working or short-term memory, intermediate-term memory, and long-term memory (which requires both acquisition and retrieval). Working memory is a short-term information storage system that functions from seconds to a few minutes. It is dependent primarily on persistent neuronal activity (i.e., continued activation of a neuron or network after cessation of the stimulus [48]) and, at a cellular level, the trafficking of glutamate receptors to the synaptic membrane [49-52]. The radial arm maze is one example of a behavioral task used to measure hippocampal-dependent working memory. In this task, mice explore a maze with eight "arms" and a single food reward on each arm. Since an arm that has been visited no longer has a food reward, reentering a previously entered arm constitutes an error. This task provides a robust assessment of visuospatial learning in rodents, as arm discrimination is primarily dictated by visual cues [53], whereas olfactory cues are crucial only when the test is conducted in total darkness [54]. Using this assay, several studies have shown that working memory efficiency is modulated by the time-of-day. Along these lines, Rawashdeh et al. [55] reported significantly better performance (i.e., fewer errors) on the radial arm maze during the day compared to the night. Interestingly, Hauber and Bareiss [3] found better working memory performance on the radial arm maze during the night. There are several potential explanations for these disparate findings, including species differences (Hauber and Bareiss used rats, while Rawashdeh et al. used mice), experimental protocol differences (Hauber and Bareiss found improvement at night following 5 days of habituation and 10 days of training, while Rawashdeh et al. found improvement during the day following 2 days of habituation and 5 days of training), lighting conditions (both studies tested rodents under dim red light $(<10$ lux) during night but used different intensities of white light during day), or the time at which training occurred (Rawashdeh et al. tested rodents at ZT2 (day) and ZT14 (night), while Hauber and Bareiss tested animals during a period of ZT5-10 for day and ZT19-24 for night).

In contrast with working memory, intermediate-term memory is a process with a time scale of several minutes to a few hours. Mechanistically, intermediate-term memory shifts away from the persistent neuronal activity process that underlies working memory and towards a stronger dependence on mechanisms downstream of neuronal activation, including persistent activation of protein kinases and inducible mRNA translation (but not gene transcription) $[39,56,57]$. Novel object location is a test of spatial 
intermediate-term memory that is gated as a function of the time-of-day. For the novel object location task, the animal first explores two objects placed in reference to a visuospatial arena (shapes on the walls of the arena differentiate each direction). Thirty to sixty minutes later, the animal is returned to the arena; meanwhile, one of the objects has been moved. More time spent exploring the object which has been moved (i.e., the object in a novel location) indicates recollection of the initial spatial location. Both Takahashi et al. [14] and Snider et al. [20] found that animals were only able to discriminate between the novel object location and the familiar object location during the night (no discrimination was observed during the day); as overall exploration was the same at all times tested, this effect did not depend on time-of-day differences in the overall amount of exploration of the objects.

In contrast to intermediate-term memory, long-term memory involves two distinct processes. The initial process of acquisition (the coding of an experience) depends on gene transcription, de novo protein translation, and alterations in neuronal connectivity but not on sustained neuronal activity [58-61]. By contrast, the second process, retrieval (accessing the coded experience), is regulated by synaptic strength and glutamate receptor trafficking at the time that the memory is accessed $[58,62,63]$ and does not require protein translation or gene transcription $[39,58]$. One of the best characterized forms of hippocampal-dependent long-term memory is contextual fear conditioning. Contextual fear conditioning involves first administering a mild electric foot shock to an animal in a visuospatial context. When the animal is returned to that context (days or even weeks later), freezing behavior indicates an association of the shock with the visuospatial context. Several studies have shown that contextual fear conditioning is gated as a function of the time-of-day. Along these lines, Chaudhury and Colwell [4] and Eckel-Mahan et al. [18] showed that long-term contextual fear conditioning memory is more efficient during the day than the night. Interestingly, Valentinuzzi et al. [19] observed more efficient contextual fear conditioning memory during the night. Possible explanations for these diverging time-of-day dependent results include differing lighting conditions (Chaudhury and Colwell and Eckel-Mahan et al. entrained to a $12 \mathrm{~h} / 12 \mathrm{~h}$ light/dark cycle, while Valentinuzzi et al. used constant dim green light with a skeleton white light photoperiod), differing measurement methods (Chaudhury and Colwell and EckelMahan et al. used seconds freezing, while Valentinuzzi et al. used latency to a beam break), and relation to baseline behavior (Chaudhury and Colwell and Eckel-Mahan et al. examined overall percent freezing, while Valentinuzzi et al. normalized each animal's beam breaks by subtracting baseline beam breaks).

Together, these studies reveal important and fundamental features of the functional effects of circadian modulation on memory processes. However, a key issue that has not yet been fully examined in rodent models relates to the ability of assays to distinguish time-of-day effects mediated by encoding from time-of-day effects that are dependent on retrieval. Along these lines, in most rodent studies of timeof-day modulation of long-term memory, the learning experience and the retrieval test are conducted at the same time-of-day (e.g., learn at early day and test at early day). Thus, it is not possible to determine whether differences are due to enhanced acquisition or enhanced retrieval. For example, a task that is better during the day could be due to better acquisition of the task; or it could be that the animals learned the task equally well at both times but retrieved the memory more efficiently during the day. Since the molecular mechanisms of encoding and retrieval are distinct, clarifying which memory process is primarily impacted by circadian rhythms should be a top priority. Work in invertebrate models $[64,65]$, as well as a handful of current studies in rodents $[4,42]$, has made strides in this direction: they designed tests of long-term memory efficiency such that the memory is retrieved at a time-of-day that is distinct from the time-of-day of the initial learning experience. Future studies examining the circadian regulation of long-term memory should seek to build on their work.

Finally, it is also important to note that time-of-day differences in performance on hippocampal-dependent tasks may be confounded by interactions with sleep/wake cycles and the circadian clock. Sleep itself is a powerful modulator of memory [66, 67], and studies of nocturnal rodents involving a day (sleep phase) time point will certainly risk sleep disruption. Moreover, both light during the night (active) phase [68] and forced or novelty-induced activity during the day (sleep) phase [69] are capable of shifting the circadian phase of the SCN. Thus, in a standard light-dark cycle with testing throughout the cycle, it is impossible to completely eliminate these confounds. However, photic effects on the circadian rhythm can be largely eliminated by using very dim red light, a common and long-standing practice in studies of circadian function [70-73]. Additionally, assaying clock-gated locomotor rhythms over the course of the memory assay can provide information on the extent of circadian disruption, if any, caused by the memory assay (as shown in Gritton et al. [12]).

\section{Circadian Timing Mechanisms}

At the cellular level, mammalian circadian rhythms are generated by a self-sustaining transcription/translation feedback loop. At its most fundamental level, this loop is centered on a basic helix-loop-helix transcription factor formed by BMAL1 and CLOCK. This heterodimeric transcription factor binds to E-box motifs (CACGTG) found within the $5^{\prime}$ regulatory regions of Period1 and Period2 (Per1/2) and Cryptochrome 1 and Cryptochrome 2 (Cry1/2) genes, thus leading to their transcription. Per and Cry transcripts are translated, dimerized, and returned to the nucleus, where they inhibit the function of the BMAL1/CLOCK dimer and hence inhibit their own transcription [74, 75]. Precisely timed degradation of PERIOD proteins relieves the repression of the BMAL1 and CLOCK complex and thus allows for a new round of Per and Cry transcription to occur. The cycling of this feedback loop, which is set to approximately 24 hours, sets the periodicity of the endogenous cellular oscillators. The phasing, periodicity, and amplitude of this molecular rhythm can be influenced by a wide 
array of intracellular effectors, including inducible kinases, histone deacetylases, phosphatases, and ubiquitin ligases (for reviews, see [76-80]); hence, this clock feedback loop can be influenced by a wide array of changes in the functional state of the cell (e.g., changes in metabolic activity, stress, and in neurons, excitability).

In mammals, circadian timing is a distributed process, with multiple peripheral organ systems and brain regions exhibiting inherent oscillatory capacity [81-83]. However, the phasing and amplitude of these distributed cell populations are set by a single brain region: the paired suprachiasmatic nucleus of the hypothalamus (SCN). The $\sim 10,000$ neurons that form the SCN utilize a variety of local paracrine and synaptic output pathways to convey clock time to peripheral oscillator populations in the brain [81, 83-86]. Further, multisynaptic output pathways allow the SCN to drive rhythmic release of endocrine hormones (e.g., melatonin and glucocorticoids) [81, 83-86], which in turn, impart rhythmic control over energy expenditure, metabolic activity, and both immune and stress responses [87-90]. Further, endocrine hormones also affect the functioning of both the SCN clock and peripheral oscillator populations in the brain [91-95].

Within the forebrain, time-keeping capacity has been reported in various regions, including the cortex, hippocampus, and the amygdala $[81,96,97]$. Consistent with this, forebrain neurons appear to express all of the essential genes required to generate cell-autonomous circadian oscillations [96-98]. Notably, the phasing of circadian rhythms varies between forebrain regions that are important for learning and memory. For example, while the hippocampus and prefrontal cortex peak in Per1 mRNA expression is at the late night, the amygdala peak of Per1 mRNA expression is at the late day [97]. The phasing of forebrain circadian rhythms is set by the SCN, and several entrainment mechanisms have been described. Along these lines, SCN-driven rhythms of corticosterone release from the adrenal glands have been shown to contribute to hippocampal rhythm phasing [91-93]. Hence, clamping corticosterone levels in mice eliminates hippocampal rhythmic expression of a period1luciferase reporter gene [92], and Woodruff et al. observed that the diurnal modulation of hippocampal-dependent fear conditioning extinction was lost in adrenalectomized rats [99]. Additionally, SCN-driven clock-gated neuronal circuits appear to alter the balance of excitatory versus inhibitory synaptic activity in the hippocampus (in particular via GABAergic innervation from the medial septum [10]). This is supported by recent work demonstrating that the spatial memory deficits in behaviorally arrhythmic Syrian hamsters are abolished following injection of pentylenetetrazol, a GABA antagonist $[9,10]$.

\section{Impacts of Circadian Disruption on Memory}

Time-of-day gating of hippocampal-dependent memory is dependent in part on the SCN. For example, SCN lesioning (which results in the loss of circadian rhythmicity) causes deficits in long-term novel object recognition [42], contextual fear conditioning and Morris water maze performance
[100]. However, no effect of SCN lesioning was observed on performance in intermediate-term novel object recognition [42, 100]. Interestingly, Fernandez et al. [101] found that while an arrhythmic Siberian hamster model had deficits in both working memory (spontaneous alternation) and long-term memory (novel object recognition), ablation of the SCN rescued both forms of memory. In a related line of work, pharmacological GABA inhibition restored performance on the novel object recognition task in arrhythmic Siberian hamsters $[9,10]$. This result was used to argue that circadian dysregulation impairs memory by increasing GABAergic inhibition influence within the hippocampus [101]. Together, these data reveal that the SCN timing system has complex context-specific effects on both working and long-term memory processes.

As with SCN lesioning, the effects of the targeted germline deletion of core clock genes (e.g., Bmal1, Cry 1/2, Clock, and Period1/2) are complex. Bmal1 is an essential component of the circadian timing system [102], and thus, Bmall knockout (KO) mice are completely arrhythmic [102, 103]. Notably, Bmal1 KO mice display deficits in habituation to a novel environment [104] and in contextual fear conditioning and Morris water maze performance [103]; however, enhancement of novel object recognition was also detected in Bmal1 KO mice [103]. Here, it is worth noting that the memory deficits in this model are somewhat difficult to interpret due to the widespread deleterious effects of Bmall deletion. Along these lines, Bmal1 $\mathrm{KO}$ mice exhibit poor overall health, including premature aging, accelerated rates of mortality, reduced body weight, increased overall sleep, loss of reproductive capabilities, disrupted metabolism, cardiomyopathy, and reduced skeletal muscle function [105-110]. Whether or not these phenotypic effects (including the effects on learning and memory) are related to a loss of circadian timing, or may also result from a loss of BMAL1 transcriptional drive that is independent of the circadian timing system, has not been fully elucidated [111].

In contrast with the complex phenotypic effects of the germline deletion of Bmal1, the phenotypic effects resulting from the genetic disruption of other core clock genes are less severe. Along these lines, with respect to overt locomotor (wheel running) activity, multiple Per1 or Per2 KO mouse lines exhibit a shortened tau (within the 0.5-1.5 hour time range) relative to WT mice [112-114]. Similarly, the Clock null line has a shortened tau $(0.4 \mathrm{~h})$ [115], whereas the Clock $^{\Delta 19 / \Delta 19}$ mutant mouse line exhibits a $4 \mathrm{hr}$ lengthening of tau and often becomes arrhythmic over an extended period in DD [116]. In tests of hippocampal-dependent memory, the Per1 $1^{\text {Brdm1/Brdm1 }}$ mouse loss-of-function line [114] display normal long-term memory in the Morris water maze and contextual fear conditioning [117], whereas a distinct Per1 KO mouse line (Per1 $1^{l d c / l d c}$ [113]) exhibits deficits on working memory in the radial arm maze $[55,96]$. Clock $^{\Delta 19 / \Delta 19}$ mutant mice [116] display deficient long-term memory in the Morris water maze yet have passive avoidance memory similar to WT controls [118]. Cry $1 / 2$ double KO mice, which are arrhythmic [119], are unable to acquire the time-place learning task (a form of place preference) [120], whereas arrhythmic Per1 $1^{\text {Brdm1/Brdm1 }} / \operatorname{Per} 2^{\text {Brdm1/Brdm1 }}$ double 
TABLE 2: Memory-related cellular signaling proteins or second messengers found to exhibit rhythmic expression or activity in the hippocampus.

\begin{tabular}{llcccc}
\hline Protein & Region & Method & Phase (peak/nadir) & Model & Reference \\
\hline cAMP & Whole hippocampus & ELISA & Day $(8 / 20)$ & C57BL/6 mice & Eckel-Mahan et al. [18] \\
cAMP & Whole hippocampus & ELISA & Day $(4 / 16)$ & C57BL/6 mice & Wardlaw et al. [103] \\
K-Ras & CA1 membrane rafts & Western & Night $(16 / 4)$ & C57BL/6 mice & Shimizu et al. [42] \\
4 EBP1 & Whole hippocampus & Western & Day $(4 / 16)$ & C57BL/6 mice & Saraf et al. [132] \\
Akt & Whole hippocampus & Western & Day $(4 / 16)$ & C57BL/6 mice & Saraf et al. [132] \\
CREB & Whole hippocampus & Western & Day $(4 / 16)$ & C57BL/6 mice & Eckel-Mahan et al. [18] \\
CREB & Whole hippocampus & Western & Day $(2 / 18)$ & C3H/HeN mice & Rawashdeh et al. [55] \\
eIF4E & Whole hippocampus & Western & Day $(4 / 16)$ & C57BL/6 mice & Saraf et al. [132] \\
ERK & CA1 & IHC & Day $(4 / 16)$ & C57BL/6 mice & Phan et al. [100] \\
ERK & Whole hippocampus & Western & Day $(2 / 14)$ & C3H/HeN mice & Rawashdeh et al. [55] \\
ERK & Whole hippocampus & Western & Day $(4 / 16)$ & C57BL/6 mice & Wardlaw et al. [103] \\
ERK & CA1 & IHC & Night $(16 / 4)$ & C57BL/6 mice & Shimizu et al. [42] \\
ERK & Whole hippocampus & Western & Day $(4 / 16)$ & C57BL/6 mice & Eckel-Mahan et al. [18] \\
GSK3 $\beta$ & CA1 & Western & Day $(9 / 17)$ & C57BL/6 mice & Besing et al. [43] \\
mTOR & Whole hippocampus & Western & Day $(4 / 16)$ & C57BL/6 mice & Saraf et al. [132] \\
S6 & Whole hippocampus & Western & Day $(4 / 16)$ & C57BL/6 mice & Saraf et al. [132] \\
Ras-GTP & Whole hippocampus & Western & Day $(8 / 20)$ & C57BL/6 mice & Eckel-Mahan et al. [18] \\
SCOP & CA1 membrane rafts & Western & Night $(16 / 4)$ & C57BL/6 mice & Shimizu et al. [42] \\
\hline
\end{tabular}

transgenic mice [114] display a learning curve indistinguishable from WT mice in the time-place learning task [121]. Overall, the complex effects of circadian gene deletion on hippocampal-dependent memory may be due in part to the unique role that each gene product plays in the core clock timing loop, the degree or type of circadian phenotype triggered by the gene deletion, and the extent to which compensatory mechanisms may be recruited to offset the effects of the gene disruption.

Recently, our lab [20] and others [42] investigated the role of non-SCN cell-autonomous circadian oscillations using conditional forebrain Bmal1 KO models, where Bmal1 is deleted in a subset of forebrain excitatory neurons (including frontal cortex and hippocampus [20,42], but excluding the hypothalamus, and hence the SCN $[20,42])$. This approach specifically eliminates ancillary clocks without impacting the master SCN clock, thus facilitating experiments addressing the role of ancillary oscillators. In these conditional Bmal1 KO mice, locomotor rhythms were indistinguishable from WT locomotor rhythms [20, 42], indicating that the functionality of the SCN clock was not affected. The physical health of these animals, notably including gross hippocampal morphology, appears unaffected by conditional Bmal1 deletion [20]. Importantly, conditional Bmal1 KO mice exhibit both a total loss of time-of-day dependent novel object location and deficits in Barnes maze performance [20] as well as abrogation of time-of-day dependent novel object recognition [42]. As the circadian deficits in this model are restricted to forebrain excitatory neurons, the cognitive deficits in these mice support a necessary role of hippocampal cell-autonomous oscillations in learning and memory.

\section{Rhythms in Kinase Signaling}

Rhythmic regulation of kinase pathways appears to play a key role in circadian modulation of learning and memory [18, 42-44]. In particular, the ERK/MAPK pathway has been especially well characterized in studies of both learning and memory $[122,123]$ and circadian timing mechanisms $[73,124]$. An initiating event in the stimulation of the ERK/ MAPK pathway is the activation (i.e., GTP loading) of the small GTPase Ras. Once in the GTP-bound form, Ras triggers a series of phosphorylation and cellular translocation events that initiates the sequential activation of Raf, MEK, and then ERK. Once activated, ERK functions as the effector kinase of the pathway, targeting numerous proteins within both the cytoplasm and the nucleus. Notably, in the SCN, the ERK/MAPK pathway is highly responsive to photic stimulation and plays a critical role in light-evoked clock resetting $[73,124,125]$. Much of the phase-shifting effects of the ERK/MAPK pathway appear to be mediated via activation of the transcription factor CREB (cAMP response element binding protein) $[73,126]$. CREB, in turn, drives the induction of the core clock gene Per1 $[127,128]$. Given these findings, and the noted work showing that the ERK/MAPK pathway plays an important role in learning and memory $[122,123]$, it appears that the ERK/MAPK pathway is ideally positioned to serve as a regulator of time-of-day dependent synaptic plasticity in the forebrain.

Interestingly, as in the SCN, several studies have reported peak ERK activation during the daytime in the hippocampus $[18,100,103]$ (Table 2). This hippocampal oscillation of ERK phosphoactivation is absent in mice with a lesioned SCN [100], indicating that SCN phase-setting signals are necessary 
for rhythmic hippocampal ERK/MAPK pathway activity. Additionally, Bmal1 KO animals do not display an oscillation in pERK [103], further indicating that this rhythm is driven by the circadian timing system. Notably, recent research proposes mechanisms by which the circadian clock may regulate the hippocampal ERK/MAPK pathway. Along these lines, the ERK inhibitor SCOP (suprachiasmatic nucleus circadian oscillatory protein) has been shown to function as a regulator of ERK activity rhythms in the hippocampus $[42,129]$. SCOP is a polypeptide that inhibits the ERK/ MAPK cascade by sequestering nucleotide-free Ras [130]. When a neuron is activated, leading to an increase in cytoplasmic $\mathrm{Ca}^{2+}$, activation of the calcium-dependent protease calpain drives rapid degradation of SCOP. This triggers the release of the nucleotide-free Ras, which rapidly binds to GTP. Ras-GTP then activates the ERK/MAPK cascade.

In the CA1 region of the hippocampus, while total SCOP expression is not regulated by time-of-day, the amount of SCOP localized to membrane rafts (where it binds Ras) is highest at night [42] (Table 2). Shimizu et al. [42] reported that learning-induced ERK activation was higher at night in WT animals, correlating with a peak in SCOP localization to membrane rafts. However, this time-of-day regulation of ERK was absent in SCOP conditional KO animals that lacked SCOP in the hippocampus [42], supporting the hypothesis that circadian gating of inducible ERK activation depends on SCOP.

In another study that examined rhythmic regulation of ERK/MAPK signaling, Rawashdeh et al. reported that PERIOD1 (PER1) enhances the nuclear translocation of pP90RSK during the day [44]. P90RSK is an ERK effector that can phosphorylate CREB [131]. Rawashdeh et al. [44] showed a late day peak in hippocampal CREB phosphorylation that was abrogated in the Perl $1^{\text {ldclldc }} \mathrm{KO}$ line, as well as a reduction in CREB-dependent transcription in cultured HT22 hippocampal cells following RNA knockdown of Per1. Moreover, coimmunoprecipitation revealed a physical interaction between pP90RSK and PER1, and inducible nuclear localization of pP90RSK was absent in Per $1^{\text {ldc } / l d c}$ mice [44]. Given the noted mechanism by which PER1 shuttles P90RSK to the nucleus, and in turn regulates CREB activity (and hence gene transcription), one would predict that the lack of Per1 protein in Per1 ${ }^{l d c / l d c}$ mice would impact long-term memory and not working memory [39]. However, Perl ${ }^{l d c / l d c}$ mice display deficits on the radial arm working memory task $[55,96]$, and Zuegger et al. found no deficits in Per1 $1^{\text {Brdm1/Brdm1 }}$ loss-of-function mice on long-term memory in the Morris water maze and contextual fear conditioning [117].

Additionally, it is noteworthy that while Shimizu et al. argued primarily for increased inducible phosphorylation of ERK during the night [42], Rawashdeh et al. and Saraf et al. argued for increased downstream effects of the ERK/MAPK pathway during the day $[44,55,132]$. Although the phasing of these ERK regulatory processes is distinct between these two studies, the proposed mechanisms may not necessarily be incompatible. Thus, using the SCN as a reference, one finds that (1) basal ERK/MAPK activity is high in subjective day and low at the subjective night and (2) that ERK/MAPK is only responsive to light during the night. These findings indicate that the circadian clock restricts specific mechanisms of ERK/MAPK activation to distinct circadian time domains [73]; additional work will be required to determine whether a similar, time-domain-specific, clock-gating mechanism exist in the hippocampus.

Another kinase posited to function as a clock-modulated regulator of hippocampal plasticity is GSK3 $\beta$ [43]. Multiple studies have revealed that GSK $3 \beta$ signaling plays a key role in hippocampal-dependent forms of learning and memory $[133,134]$. Interestingly, Besing et al. [43] demonstrated that in the CA1 cell layer of the hippocampus, GSK3 $\beta$ activity was rhythmic, with a peak occurring during the night. Further, Besing et al. [43] found that the inhibition of GSK3 $\beta$ diminished LTP only during the night (this finding is further discussed in Section 5). GSK3 $\beta$ is a constitutively active kinase that is inhibited by phosphorylation at Serine 9. Although the upstream mechanism that imparts rhythmicity onto GSK3 $\beta$ activity is not yet clear, Besing et al. [43] speculate that phosphorylation at Serine 9 by the kinase Akt could underlie the rhythm in GSK3 $\beta$ activity in the hippocampus. Notably, expression of the Akt 2 transcript is regulated by the circadian clock in the liver [135], and phosphorylation of Akt follows a circadian rhythm in cardiomyocytes [136].

At the level of clock-gated cellular timing, GSK3 $\beta$ has been found to affect the core clock transcriptional loop. In the hippocampus, both BMAL1 rhythms and period2-luciferase reporter rhythms were disrupted in knock-in mice with constitutively high GSK3 $\beta$ activity [43]. Mechanistically, GSK3 $\beta$ has been shown to phosphorylate BMAL1, which led to an accelerated rate of degradation [137]. Interestingly, in the liver, Akt has been shown to phosphorylate BMAL1, leading to its increased cytoplasmic localization and, in turn, a decrease in its transcriptional activity [138]. Together, these data indicate that an Akt/GSK3 $\beta$ signaling cassette may function at multiple points, both within the core clock feedback loop and within clock-gated processes to modulate neuronal plasticity over the 24-hour cycle.

Finally, Saraf et al. [132] reported that the circadian clock modulates the activation state of mTOR (mammalian target of rapamycin), a key regulator of inducible mRNA translation in the hippocampus. Interestingly, timed daily inhibition of mRNA translation via the injection of anisomycin markedly reduced the efficiency of contextual fear recall [132], thus raising the prospect that circadian gating of mRNA translation plays a critical role in long-term memory persistence or retrieval.

\section{Long-Term Potentiation and the Circadian Clock}

Long-term potentiation (LTP) is a form of synaptic plasticity that is an underlying element in the formation and maintenance of a wide range of memory processes [39, 139, 140]. LTP can be subdivided into two stages: early LTP (E-LTP) and late LTP (L-LTP). Each stage of LTP contributes to distinctive memory processes. E-LTP occurs within the first hour of stimulation and potentiates synaptic strength in early, intermediate-term, and long-term memory by 
trafficking of glutamate receptors to the postsynaptic membrane $[39,51]$. L-LTP, occurring hours poststimulation, is important for intermediate-term and long-term memory and requires gene transcription and translation for maintenance [39].

The population spike (PS) amplitude, duration, and rate of decay of LTP have all been shown to vary based on timeof-day in mice [43, 141-143]. Chaudhury et al. [143] demonstrated that PS amplitude and field excitatory postsynaptic potential (fEPSP) slope were increased in mouse hippocampal slices that were obtained in subjective night, compared to the day. Further, Chaudhury et al. [143] reported that there was a longer duration of the enhanced postsynaptic response in the subjective night compared to day. Interestingly, the enhanced PS amplitude and fEPSP slope during subjective night was consistent between mice kept on a 12hour light/dark schedule and those kept in constant darkness [143], indicating that this component of LTP is driven by a circadian clock-gated mechanism. Of note, other studies have reported more efficient LTP induction in the subjective day in rats [144] and Syrian hamsters [145]; therefore, there are likely to be species-specific mechanisms by which the clock regulates LTP induction over the 24-hour cycle. Furthermore, germline Bmal1 knockout mice showed decreased LTP amplitude during the day compared to wild-type animals [103]. Of note, to date, no work has shown if the diurnal difference in LTP PS amplitude or fEPSP slope is abolished in Bmall knockout mice.

Recent work has identified several kinase signaling pathways that may contribute to time-of-day dependent changes in LTP. One such diurnally regulated kinase is GSK $3 \beta$. Notably, increased GSK $3 \beta$ activity was found to be correlated with enhanced LTP at night, and the inhibition of GSK3 $\beta$ diminished LTP only during the night [43]. Interestingly, in a constitutively active GSK $3 \beta$ knock-in mouse, overall LTP was enhanced and was still higher at night than during the day. While the downstream pathway by which GSK3 $\beta$ modulates LTP has not been demonstrated, GSK3 $\beta$ is known to phosphorylate a range of targets involved in neuronal function and memory, including CREB, tau, $\beta$-catenin, MAP1B, and PS-1 [146].

Given that circadian modulation of LTP was still observed in the constitutively active GSK $3 \beta$ knock-in mouse [43], GSK $3 \beta$ is likely not the only pathway regulating timeof-day dependent changes in LTP. Notably, activation of ERK (another kinase diurnally regulated in the hippocampus [18]) has also been shown to play a critical role in induction of early LTP [123] and for the maintenance of L-LTP. The effects on E-LTP may be ascribed to ERK regulation of the Kv4.2 channel, which leads to a reduction in its conductance properties, and in turn, an increase in hippocampal cellular excitability [147, 148]. The effects of MAPK signaling on L-LTP have been shown to result from ERK-dependent activation of CREB-dependent transcription [123, 149]. Given the key role that ERK/MAPK signaling plays in memory formation coupled with noted studies showing ERK activation rhythms in the hippocampus, it is quite tempting to posit that these daily oscillations in ERK activity could contribute to time-of-day dependent changes in learning and memory formation. As a starting point, however, no study to date (to our knowledge) has demonstrated a direct link between the rhythmic regulation of ERK activity and the clock-gating of LTP.

Though work to date indicates that kinase pathways contribute to circadian modulation of intermediate and long-term memory, there is a distinct lack of evidence at the molecular level as to how working memory is modulated by the clock (see Table 1 for a summary of circadian differences in working memory). Here, we provide several mechanisms by which this process could occur. One possible mechanism is that the clock gates E-LTP induction, which in turn, could underlie time-of-day differences in working memory efficiency. At a mechanistic level, clock-gated changes in glutamate receptor trafficking efficiency may underlie this process. As noted, E-LTP induction is dependent on the rapid trafficking of AMPA receptors containing the GluA1 subunit to the postsynaptic membrane [51, 150], and recent work has demonstrated that glutamate receptor trafficking is regulated by clock-gated signaling pathways. Notably, Ras-GTP (a kinase in the ERK pathway) has been shown to induce trafficking of GluR1 to synapses [151], and GSK3 $\beta$ promotes membrane localization of NMDA receptors [152]. While circadian rhythms in glutamate receptor trafficking have not been reported, this may be a worthwhile area of inquiry. Another possibility is related to clock modulation of dendritic spine density. In support of this idea, Ikeda et al. [153] reported an oscillation in CA1 synaptic spine density, with a peak density occurring during the early subjective night, a time point when peak performance on working memory tasks is observed (see Table 1).

\section{Conclusions}

While the emphasis of this review is on clock gating of excitatory neuronal plasticity, it is important to place these processes within a broader hippocampal context. Notably, the hippocampus is a complex cellular environment with multiple cell types, including excitatory pyramidal cells, inhibitory interneurons, microglia, astrocytes, and oligodendrocytes [154]. Both glia [98, 155] and interneurons [156] have intrinsic circadian rhythms, and both cell types impact learning and memory [157-159]. Further, recent evidence has demonstrated that astrocytes are crucial for setting circadian timing within the SCN $[160,161]$. Thus, the work described here, which focuses largely on excitatory neurons, may only be a piece of a much larger intercellular network of neurons and glia through which the clock modulates cognition.

Clearly, a deeper understanding of how the circadian clock gates hippocampal circuitry should be a priority for further study. Potential new avenues of inquiry could include, for instance, synaptic scaling, a process by which neurons regulate their overall level of excitability [66, 162, 163]. While much of the research on synaptic scaling has focused on the effects of sleep, circadian rhythms likely also play a part in this process [164-166]. Further, work that explores the potential impacts that cognitive or neurodegenerative disorders have on clock gating of kinase signaling or clock 
gating of synaptic plasticity may provide clues regarding the relationship between disease states and deficits in learning and memory. Finally, given the tight, intertwined, relationship between sleep and circadian timing, further experimentation that explores the relative contribution of each process to the modulation of cellular plasticity and cognition is highly merited. Clearly, we are at the beginning of a new and exciting era of work that will provide fundamental insights into the powerful and far-reaching effects that the circadian timing system has on cognition.

\section{Conflicts of Interest}

The authors declare that there is no conflict of interest regarding the publication of this paper.

\section{Acknowledgments}

This study was supported by the National Institutes of Health (Grant nos. MH103361, NS066345, and NS091302) and the National Science Foundation (Grant no. 1354612).

\section{References}

[1] J. A. Davies, V. Navaratnam, and P. H. Redfern, "A 24-hour rhythm in passive-avoidance behaviour in rats," Psychopharmacologia, vol. 32, no. 2, pp. 211-214, 1973.

[2] H. J. Hoffmann and D. Balschun, "Circadian differences in maze performance of C57BI/6 Ola mice," Behavioural Processes, vol. 27, no. 2, pp. 77-83, 1992.

[3] W. Hauber and A. Bareiss, "Facilitative effects of an adenosine $A_{1} / A_{2}$ receptor blockade on spatial memory performance of rats: selective enhancement of reference memory retention during the light period," Behavioural Brain Research, vol. 118, no. 1, pp. 43-52, 2001.

[4] D. Chaudhury and C. S. Colwell, "Circadian modulation of learning and memory in fear-conditioned mice," Behavioural Brain Research, vol. 133, no. 1, pp. 95-108, 2002.

[5] L. M.-C. Wang, J. M. Dragich, T. Kudo et al., "Expression of the circadian clock gene Period2 in the hippocampus: possible implications for synaptic plasticity and learned behaviour," ASN Neuro, vol. 1, no. 3, article AN20090020, 2009.

[6] C. Liston, J. M. Cichon, F. Jeanneteau, Z. Jia, M. V. Chao, and W.-B. Gan, "Circadian glucocorticoid oscillations promote learning-dependent synapse formation and maintenance," Nature Neuroscience, vol. 16, no. 6, pp. 698-705, 2013.

[7] G. Winocur and L. Hasher, "Aging and time-of-day effects on cognition in rats," Behavioral Neuroscience, vol. 113, no. 5, pp. 991-997, 1999.

[8] G. Winocur and L. Hasher, "Age and time-of-day effects on learning and memory in a non-matching-to-sample test," Neurobiology of Aging, vol. 25, no. 8, pp. 1107-1115, 2004.

[9] N. F. Ruby, C. E. Hwang, C. Wessells et al., "Hippocampaldependent learning requires a functional circadian system," Proceedings of the National Academy of Sciences, vol. 105, no. 40, pp. 15593-15598, 2008.

[10] N. F. Ruby, F. Fernandez, A. Garrett et al., "Spatial memory and long-term object recognition are impaired by circadian arrhythmia and restored by the $\mathrm{GABA}_{\mathrm{A}}$ antagonist pentylenetetrazole," PLoS One, vol. 8, no. 8, article e72433, 2013.
[11] F. K. Stephan and N. S. Kovacevic, "Multiple retention deficit in passive avoidance in rats is eliminated by suprachiasmatic lesions," Behavioral Biology, vol. 22, no. 4, pp. 456-462, 1978.

[12] H. J. Gritton, A. Kantorowski, M. Sarter, and T. M. Lee, "Bidirectional interactions between circadian entrainment and cognitive performance," Learning \& Memory, vol. 19, no. 3, pp. 126-141, 2012.

[13] R. R. Pagano and R. H. Lovely, "Diurnal cycle and ACTH facilitation of shuttlebox avoidance," Physiology \& Behavior, vol. 8, no. 4, pp. 721-723, 1972.

[14] Y. Takahashi, K. Sawa, and T. Okada, "The diurnal variation of performance of the novel location recognition task in male rats," Behavioural Brain Research, vol. 256, pp. 488493, 2013.

[15] W. B. Ghiselli and R. A. Patton, "Diurnal variation in performance of free-operant avoidance behavior of rats," Psychological Reports, vol. 38, no. 1, pp. 83-90, 1976.

[16] J. W. Rudy and C. R. Pugh, "Time of conditioning selectively influences contextual fear conditioning: further support for a multiple-memory systems view of fear conditioning," Journal of Experimental Psychology: Animal Behavior Processes, vol. 24, no. 3, pp. 316-324, 1998.

[17] C. H. Ko, R. J. McDonald, and M. R. Ralph, "The suprachiasmatic nucleus is not required for temporal gating of performance on a reward-based learning and memory task," Biological Rhythm Research, vol. 34, no. 2, pp. 177192, 2003.

[18] K. L. Eckel-Mahan, T. Phan, S. Han et al., "Circadian oscillation of hippocampal MAPK activity and cAMP: implications for memory persistence," Nature Neuroscience, vol. 11, no. 9, pp. 1074-1082, 2008.

[19] V. S. Valentinuzzi, D. E. Kolker, M. H. Vitaterna, E. A. M. Ferrari, J. S. Takahashi, and F. W. Turek, "Effect of circadian phase on context and cued fear conditioning in C57BL/6J mice," Animal Learning \& Behavior, vol. 29, no. 2, pp. 133$142,2001$.

[20] K. H. Snider, H. Dziema, S. Aten et al., "Modulation of learning and memory by the targeted deletion of the circadian clock gene Bmal1 in forebrain circuits," Behavioural Brain Research, vol. 308, pp. 222-235, 2016.

[21] L. C. Lyons, M. S. Collado, O. Khabour, C. L. Green, and A. Eskin, "The circadian clock modulates core steps in longterm memory formation in Aplysia," Journal of Neuroscience, vol. 26, no. 34, pp. 8662-8671, 2006.

[22] L. C. Lyons and G. Roman, "Circadian modulation of shortterm memory in Drosophila," Learning \& Memory, vol. 16, no. 1, pp. 19-27, 2008.

[23] K. P. Wright Jr., J. T. Hull, and C. A. Czeisler, "Relationship between alertness, performance, and body temperature in humans," American Journal of Physiology - Regulatory, Integrative and Comparative Physiology, vol. 283, no. 6, pp. R1370-R1377, 2002.

[24] K. Cho, A. Ennaceur, J. C. Cole, and C. K. Suh, "Chronic jet lag produces cognitive deficits," The Journal of Neuroscience, vol. 20, no. 6, article RC66, 2000.

[25] K. Cho, "Chronic 'jet lag' produces temporal lobe atrophy and spatial cognitive deficits," Nature Neuroscience, vol. 4, no. 6, pp. 567-568, 2001.

[26] D. B. Boivin and P. Boudreau, "Impacts of shift work on sleep and circadian rhythms," Pathologie Biologie, vol. 62, no. 5, pp. 292-301, 2014. 
[27] J.-C. Marquié, P. Tucker, S. Folkard, C. Gentil, and D. Ansiau, "Chronic effects of shift work on cognition: findings from the VISAT longitudinal study," Occupational \& Environmental Medicine, vol. 72, no. 4, pp. 258-264, 2015.

[28] A. Videnovic, A. S. Lazar, R. A. Barker, and S. Overeem, "The clocks that time us'-circadian rhythms in neurodegenerative disorders," Nature Reviews Neurology, vol. 10, no. 12, pp. 683-693, 2014.

[29] E. S. Musiek, "Circadian clock disruption in neurodegenerative diseases: cause and effect?," Frontiers in Pharmacology, vol. 6, 2015.

[30] E. S. Musiek, "Circadian rhythms in AD pathogenesis: a critical appraisal," Current Sleep Medicine Reports, vol. 3, no. 2, pp. 85-92, 2017.

[31] E. S. Musiek, D. D. Xiong, and D. M. Holtzman, "Sleep, circadian rhythms, and the pathogenesis of Alzheimer disease," Experimental \& Molecular Medicine, vol. 47, no. 3, article e148, 2015.

[32] A. Videnovic and D. Golombek, "Circadian and sleep disorders in Parkinson's disease," Experimental Neurology, vol. 243, pp. 45-56, 2013.

[33] S. Martínez-Horta and J. Kulisevsky, "Is all cognitive impairment in Parkinson's disease "mild cognitive impairment"?," Journal of Neural Transmission, vol. 118, no. 8, pp. 11851190, 2011.

[34] L. D. Willison, T. Kudo, D. H. Loh, D. Kuljis, and C. S. Colwell, "Circadian dysfunction may be a key component of the non-motor symptoms of Parkinson's disease: insights from a transgenic mouse model," Experimental Neurology, vol. 243, pp. 57-66, 2013

[35] A. J. Morton, "Circadian and sleep disorder in Huntington's disease," Experimental Neurology, vol. 243, pp. 3444, 2013

[36] P. N. Pallier, E. S. Maywood, Z. Zheng et al., "Pharmacological imposition of sleep slows cognitive decline and reverses dysregulation of circadian gene expression in a transgenic mouse model of Huntington's disease," Journal of Neuroscience, vol. 27, no. 29, pp. 7869-7878, 2007.

[37] P. N. Pallier and A. J. Morton, "Management of sleep/wake cycles improves cognitive function in a transgenic mouse model of Huntington's disease," Brain Research, vol. 1279, pp. 90-98, 2009.

[38] D. M. Smith and S. J. Y. Mizumori, "Hippocampal place cells, context, and episodic memory," Hippocampus, vol. 16, no. 9, pp. 716-729, 2006.

[39] E. R. Kandel, Y. Dudai, and M. R. Mayford, "The molecular and systems biology of memory," Cell, vol. 157, no. 1, pp. 163-186, 2014.

[40] E. R. Kandel, "The molecular biology of memory: cAMP, PKA, CRE, CREB-1, CREB-2, and CPEB," Molecular Brain, vol. 5, no. 1, p. 14, 2012.

[41] Z. Xia and D. R. Storm, "Role of signal transduction crosstalk between adenylyl cyclase and MAP kinase in hippocampusdependent memory," Learning \& Memory, vol. 19, no. 9, pp. 369-374, 2012.

[42] K. Shimizu, Y. Kobayashi, E. Nakatsuji et al., "SCOP/ PHLPP $1 \beta$ mediates circadian regulation of long-term recognition memory," Nature Communications, vol. 7, article 12926, 2016

[43] R. C. Besing, C. O. Rogers, J. R. Paul et al., "GSK3 activity regulates rhythms in hippocampal clock gene expression and synaptic plasticity," Hippocampus, vol. 27, no. 8 , pp. 890-898, 2017.

[44] O. Rawashdeh, A. Jilg, E. Maronde, J. Fahrenkrug, and J. H. Stehle, "Period 1 gates the circadian modulation of memoryrelevant signaling in mouse hippocampus by regulating the nuclear shuttling of the CREB kinase pP90RSK," Journal of Neurochemistry, vol. 138, no. 5, pp. 731-745, 2016.

[45] G. R. I. Barker and E. C. Warburton, "When is the hippocampus involved in recognition memory?," Journal of Neuroscience, vol. 31, no. 29, pp. 10721-10731, 2011.

[46] R. D. Burwell, "Corticohippocampal contributions to spatial and contextual learning," Journal of Neuroscience, vol. 24, no. 15, pp. 3826-3836, 2004.

[47] C. R. Flavell and J. L. C. Lee, "Post-training unilateral amygdala lesions selectively impair contextual fear memories," Learning \& Memory, vol. 19, no. 6, pp. 256-263, 2012.

[48] M. R. Riley and C. Constantinidis, "Role of prefrontal persistent activity in working memory," Frontiers in Systems Neuroscience, vol. 9, 2016.

[49] O. Barak and M. Tsodyks, "Working models of working memory," Current Opinion in Neurobiology, vol. 25, pp. 2024, 2014.

[50] M. E. Hasselmo and C. E. Stern, "Mechanisms underlying working memory for novel information," Trends in Cognitive Sciences, vol. 10, no. 11, pp. 487-493, 2006.

[51] D. J. Sanderson, S. B. McHugh, M. A. Good et al., "Spatial working memory deficits in GluA1 AMPA receptor subunit knockout mice reflect impaired short-term habituation: evidence for Wagner's dual-process memory model," Neuropsychologia, vol. 48, no. 8, pp. 2303-2315, 2010.

[52] D. J. Sanderson, M. A. Good, P. H. Seeburg, R. Sprengel, J. N. P. Rawlins, and D. M. Bannerman, "Chapter 9 the role of the GluR-A (GluR1) AMPA receptor subunit in learning and memory," Progress in Brain Research, vol. 169, pp. 159178, 2008.

[53] O. Buresová and J. Bures, "Role of olfactory cues in the radial maze performance of rats," Behavioural Brain Research, vol. 3, no. 3, pp. 405-409, 1981.

[54] P. Lavenex and F. Schenk, "Integration of olfactory information in a spatial representation enabling accurate arm choice in the radial arm maze," Learning \& Memory, vol. 2, no. 6, pp. 299-319, 1996.

[55] O. Rawashdeh, A. Jilg, P. Jedlicka et al., "PERIOD1 coordinates hippocampal rhythms and memory processing with daytime," Hippocampus, vol. 24, no. 6, pp. 712-723, 2014.

[56] M. Michel, C. L. Green, J. S. Gardner, C. L. Organ, and L. C. Lyons, "Massed training-induced intermediate-term operant memory in Aplysia requires protein synthesis and multiple persistent kinase cascades," Journal of Neuroscience, vol. 32, no. 13, pp. 4581-4591, 2012.

[57] M. T. Grimes, M. Smith, X. Li, A. Darby-King, C. W. Harley, and J. H. McLean, "Mammalian intermediate-term memory: new findings in neonate rat," Neurobiology of Learning and Memory, vol. 95, no. 3, pp. 385-391, 2011.

[58] S. Tonegawa, M. Pignatelli, D. S. Roy, and T. J. Ryan, "Memory engram storage and retrieval," Current Opinion in Neurobiology, vol. 35, pp. 101-109, 2015.

[59] N. J. Broadbent, L. R. Squire, and R. E. Clark, "Sustained dorsal hippocampal activity is not obligatory for either the maintenance or retrieval of long-term spatial memory," Hippocampus, vol. 20, no. 12, pp. 1366-1375, 2010. 
[60] T. J. Jarome and F. D. Lubin, "Epigenetic mechanisms of memory formation and reconsolidation," Neurobiology of Learning and Memory, vol. 115, pp. 116-127, 2014.

[61] R. Romero-Granados, Á. Fontán-Lozano, J. M. DelgadoGarcía, and Á. M. Carrión, "From learning to forgetting: behavioral, circuitry, and molecular properties define the different functional states of the recognition memory trace," Hippocampus, vol. 20, no. 5, pp. 584-595, 2010.

[62] J. Lopez, K. Gamache, R. Schneider, and K. Nader, "Memory retrieval requires ongoing protein synthesis and NMDA receptor activity-mediated AMPA receptor trafficking," Journal of Neuroscience, vol. 35, no. 6, pp. 2465-2475, 2015.

[63] B. N. Cazakoff and J. G. Howland, "AMPA receptor endocytosis in rat perirhinal cortex underlies retrieval of object memory," Learning \& Memory, vol. 18, no. 11, pp. 688692, 2011.

[64] O. Rawashdeh, N. H. de Borsetti, G. Roman, and G. M. Cahill, "Melatonin suppresses nighttime memory formation in zebrafish," Science, vol. 318, no. 5853, pp. 1144-1146, 2007.

[65] L. C. Lyons, O. Rawashdeh, A. Katzoff, A. J. Susswein, and A. Eskin, "Circadian modulation of complex learning in diurnal and nocturnal Aplysia," Proceedings of the National Academy of Sciences of the United States of America, vol. 102, no. 35, pp. 12589-12594, 2005.

[66] F. Raven, E. A. Van der Zee, P. Meerlo, and R. Havekes, "The role of sleep in regulating structural plasticity and synaptic strength: implications for memory and cognitive function," Sleep Medicine Reviews, 2017.

[67] A. P. Vorster and J. Born, "Sleep and memory in mammals, birds and invertebrates," Neuroscience \& Biobehavioral Reviews, vol. 50, pp. 103-119, 2015.

[68] J. J. Milette and F. W. Turek, "Circadian and photoperiodic effects of brief light pulses in male Djungarian hamsters," Biology of Reproduction, vol. 35, no. 2, pp. 327-335, 1986.

[69] M. C. Antle, F. Tse, S. J. Koke, R. Sterniczuk, and K. Hagel, "Non-photic phase shifting of the circadian clock: role of the extracellular signal-responsive kinases I/II/mitogenactivated protein kinase pathway," European Journal of Neuroscience, vol. 28, no. 12, pp. 2511-2518, 2008.

[70] A. Hirano, D. Braas, Y.-H. Fu, and L. J. Ptáček, "FAD regulates CRYPTOCHROME protein stability and circadian clock in mice," Cell Reports, vol. 19, no. 2, pp. 255-266, 2017.

[71] G. R. Yamakawa, P. Basu, F. Cortese et al., "The cholinergic forebrain arousal system acts directly on the circadian pacemaker," Proceedings of the National Academy of Sciences, vol. 113, no. 47, pp. 13498-13503, 2016.

[72] J. LeSauter, T. Bhuiyan, T. Shimazoe, and R. Silver, "Circadian trafficking of Calbindin-ir in fibers of SCN neurons," Journal of Biological Rhythms, vol. 24, no. 6, pp. 488496, 2009.

[73] K. Obrietan, S. Impey, and D. R. Storm, "Light and circadian rhythmicity regulate MAP kinase activation in the suprachiasmatic nuclei," Nature Neuroscience, vol. 1, no. 8, pp. 693700, 1998.

[74] L. P. Shearman, S. Sriram, D. R. Weaver et al., "Interacting molecular loops in the mammalian circadian clock," Science, vol. 288, no. 5468, pp. 1013-1019, 2000.

[75] A. M. Sangoram, L. Saez, M. P. Antoch et al., "Mammalian circadian autoregulatory loop: a timeless ortholog and mPer1 interact and negatively regulate CLOCK-BMAL1-induced transcription," Neuron, vol. 21, no. 5, pp. 1101-1113, 1998.
[76] M. Gallego and D. M. Virshup, "Post-translational modifications regulate the ticking of the circadian clock," Nature Reviews Molecular Cell Biology, vol. 8, no. 2, pp. 139-148, 2007.

[77] U. Bhadra, N. Thakkar, P. Das, and M. Pal Bhadra, "Evolution of circadian rhythms: from bacteria to human," Sleep Medicine, vol. 35, pp. 49-61, 2017.

[78] R. Papazyan, Y. Zhang, and M. A. Lazar, "Genetic and epigenomic mechanisms of mammalian circadian transcription," Nature Structural \& Molecular Biology, vol. 23, no. 12, pp. 1045-1052, 2016.

[79] L. Tasselli and K. F. Chua, "Methylation gets into rhythm with NAD ${ }^{+}$-SIRT1," Nature Structural \& Molecular Biology, vol. 22, no. 4, pp. 275-277, 2015.

[80] C. L. Partch, C. B. Green, and J. S. Takahashi, "Molecular architecture of the mammalian circadian clock," Trends in Cell Biology, vol. 24, no. 2, pp. 90-99, 2014.

[81] C. Guilding and H. D. Piggins, "Challenging the omnipotence of the suprachiasmatic timekeeper: are circadian oscillators present throughout the mammalian brain?," European Journal of Neuroscience, vol. 25, no. 11, pp. 3195-3216, 2007.

[82] R. Buijs, R. Salgado, E. Sabath, and C. Escobar, "Chapter four - peripheral circadian oscillators," Progress in Molecular Biology and Translational Science, vol. 119, pp. 83103, 2013.

[83] C. Dibner, U. Schibler, and U. Albrecht, "The mammalian circadian timing system: organization and coordination of central and peripheral clocks," Annual Review of Physiology, vol. 72, no. 1, pp. 517-549, 2010.

[84] M. Menaker, Z. C. Murphy, and M. T. Sellix, "Central control of peripheral circadian oscillators," Current Opinion in Neurobiology, vol. 23, no. 5, pp. 741-746, 2013.

[85] R. Y. Moore and V. B. Eichler, "Loss of a circadian adrenal corticosterone rhythm following suprachiasmatic lesions in the rat," Brain Research, vol. 42, no. 1, pp. 201-206, 1972.

[86] J. D. Li, W. P. Hu, and Q. Y. Zhou, "Chapter 7 - the circadian output signals from the suprachiasmatic nuclei," Progress in Brain Research, vol. 199, pp. 119-127, 2012.

[87] S. M. Bailey, U. S. Udoh, and M. E. Young, "Circadian regulation of metabolism," Journal of Endocrinology, vol. 222, no. 2, pp. R75-R96, 2014.

[88] N. Cermakian, T. Lange, D. Golombek et al., "Crosstalk between the circadian clock circuitry and the immune system," Chronobiology International, vol. 30, no. 7, pp. 870888, 2013.

[89] D. Landgraf, M. J. McCarthy, and D. K. Welsh, "Circadian clock and stress interactions in the molecular biology of psychiatric disorders," Current Psychiatry Reports, vol. 16, no. 10, p. 483, 2014.

[90] P. Tognini, C. A. Thaiss, E. Elinav, and P. Sassone-Corsi, "Circadian coordination of antimicrobial responses," Cell Host \& Microbe, vol. 22, no. 2, pp. 185-192, 2017.

[91] E. R. Woodruff, L. E. Chun, L. R. Hinds, and R. L. Spencer, "Diurnal corticosterone presence and phase modulate clock gene expression in the male rat prefrontal cortex," Endocrinology, vol. 157, no. 4, pp. 1522-1534, 2016.

[92] M. J. Gilhooley, S. B. Pinnock, and J. Herbert, "Rhythmic expression of per 1 in the dentate gyrus is suppressed by corticosterone: implications for neurogenesis," Neuroscience Letters, vol. 489, no. 3, pp. 177-181, 2011. 
[93] B. L. Conway-Campbell, R. A. Sarabdjitsingh, M. A. McKenna et al., "Glucocorticoid ultradian rhythmicity directs cyclical gene pulsing of the clock gene period 1 in rat hippocampus," Journal of Neuroendocrinology, vol. 22, no. 10, pp. 1093-1100, 2010.

[94] J. Vriend and R. J. Reiter, "Melatonin feedback on clock genes: a theory involving the proteasome," Journal of Pineal Research, vol. 58, no. 1, pp. 1-11, 2015.

[95] M. D. C. Belle, "Circadian tick-talking across the neuroendocrine system and suprachiasmatic nuclei circuits: the enigmatic communication between the molecular and electrical membrane clocks," Journal of Neuroendocrinology, vol. 27, no. 7, pp. 567-576, 2015.

[96] A. Jilg, S. Lesny, N. Peruzki et al., "Temporal dynamics of mouse hippocampal clock gene expression support memory processing," Hippocampus, vol. 20, no. 3, pp. 377-388, 2010.

[97] L. E. Chun, E. R. Woodruff, S. Morton, L. R. Hinds, and R. L. Spencer, "Variations in phase and amplitude of rhythmic clock gene expression across prefrontal cortex, hippocampus, amygdala, and hypothalamic paraventricular and suprachiasmatic nuclei of male and female rats," Journal of Biological Rhythms, vol. 30, no. 5, pp. 417-436, 2015.

[98] H.-Y. M. Cheng, M. Alvarez-Saavedra, H. Dziema, Y. S. Choi, A. Li, and K. Obrietan, "Segregation of expression of mPeriod gene homologs in neurons and glia: possible divergent roles of mPeriod 1 and mPeriod 2 in the brain," Human Molecular Genetics, vol. 18, no. 16, pp. 3110-3124, 2009.

[99] E. R. Woodruff, B. N. Greenwood, L. E. Chun, S. Fardi, L. R. Hinds, and R. L. Spencer, "Adrenal-dependent diurnal modulation of conditioned fear extinction learning," Behavioural Brain Research, vol. 286, pp. 249-255, 2015.

[100] T. H. Phan, G. C.-K. Chan, C. B. Sindreu, K. L. Eckel-Mahan, and D. R. Storm, "The diurnal oscillation of MAP (mitogenactivated protein) kinase and adenylyl cyclase activities in the hippocampus depends on the suprachiasmatic nucleus," Journal of Neuroscience, vol. 31, no. 29, pp. 1064010647, 2011.

[101] F. Fernandez, D. Lu, P. Ha et al., "Dysrhythmia in the suprachiasmatic nucleus inhibits memory processing," Science, vol. 346, no. 6211, pp. 854-857, 2014.

[102] M. K. Bunger, L. D. Wilsbacher, S. M. Moran et al., "Mop3 is an essential component of the master circadian pacemaker in mammals," Cell, vol. 103, no. 7, pp. 1009-1017, 2000.

[103] S. M. Wardlaw, T. X. Phan, A. Saraf, X. Chen, and D. R. Storm, "Genetic disruption of the core circadian clock impairs hippocampus-dependent memory," Learning \& Memory, vol. 21, no. 8, pp. 417-423, 2014.

[104] A. A. Kondratova, Y. V. Dubrovsky, M. P. Antoch, and R. V. Kondratov, "Circadian clock proteins control adaptation to novel environment and memory formation," Aging, vol. 2, no. 5, pp. 285-297, 2010.

[105] A. Laposky, A. Easton, C. Dugovic, J. Walisser, C. Bradfield, and F. Turek, "Deletion of the mammalian circadian clock gene BMAL1/Mop3 alters baseline sleep architecture and the response to sleep deprivation," Sleep, vol. 28, no. 4, pp. 395-410, 2005.

[106] Y. Sun, Z. Yang, Z. Niu et al., "The mortality of MOP3 deficient mice with a systemic functional failure," Journal of Biomedical Science, vol. 13, no. 6, pp. 845-851, 2006.

[107] J. L. Andrews, X. Zhang, J. J. McCarthy et al., "CLOCK and BMAL1 regulate $M y o D$ and are necessary for maintenance of skeletal muscle phenotype and function," Proceedings of the National Academy of Sciences, vol. 107, no. 44, pp. 19090-19095, 2010.

[108] M. J. Boden, T. J. Varcoe, A. Voultsios, and D. J. Kennaway, "Reproductive biology of female Bmal1 null mice," Reproduction, vol. 139, no. 6, pp. 1077-1090, 2010.

[109] B. Marcheva, K. M. Ramsey, E. D. Buhr et al., "Disruption of the clock components CLOCK and BMAL1 leads to hypoinsulinaemia and diabetes," Nature, vol. 466, no. 7306, pp. 627-631, 2010.

[110] M. Lefta, K. S. Campbell, H.-Z. Feng, J.-P. Jin, and K. A. Esser, "Development of dilated cardiomyopathy in Bmal1-deficient mice," American Journal of Physiology-Heart and Circulatory Physiology, vol. 303, no. 4, pp. H475-H485, 2012.

[111] P. L. Lowrey and J. S. Takahashi, "Chapter 6 - genetics of circadian rhythms in mammalian model organisms," Advances in Genetics, vol. 74, pp. 175-230, 2011.

[112] N. Cermakian, L. Monaco, M. P. Pando, A. Dierich, and P. Sassone-Corsi, "Altered behavioral rhythms and clock gene expression in mice with a targeted mutation in the Period1 gene," The EMBO Journal, vol. 20, no. 15, pp. 3967-3974, 2001.

[113] K. Bae, X. Jin, E. S. Maywood, M. H. Hastings, S. M. Reppert, and D. R. Weaver, "Differential functions of mPer1, mPer2, and mPer3 in the SCN circadian clock," Neuron, vol. 30, no. 2, pp. 525-536, 2001.

[114] B. Zheng, U. Albrecht, K. Kaasik et al., "Nonredundant roles of the mPer 1 and mPer 2 genes in the mammalian circadian clock," Cell, vol. 105, no. 5, pp. 683-694, 2001.

[115] J. P. DeBruyne, E. Noton, C. M. Lambert, E. S. Maywood, D. R. Weaver, and S. M. Reppert, "A clock shock: mouse CLOCK is not required for circadian oscillator function," Neuron, vol. 50, no. 3, pp. 465-477, 2006.

[116] M. Vitaterna, D. King, A. Chang et al., "Mutagenesis and mapping of a mouse gene, clock, essential for circadian behavior," Science, vol. 264, no. 5159, pp. 719-725, 1994.

[117] M. Zueger, A. Urani, S. Chourbaji et al., "mPer1 and mPer2 mutant mice show regular spatial and contextual learning in standardized tests for hippocampus-dependent learning," Journal of Neural Transmission, vol. 113, no. 3, pp. 347356, 2006.

[118] H. Sei, K. Oishi, A. Sano et al., "Clock mutant mice with Jcl/ ICR background shows an impaired learning ability in water maze, but not in passive avoidance, at the beginning of dark phase," Congenital Anomalies, vol. 46, no. 2, pp. 81-85, 2006.

[119] G. T. van der Horst, M. Muijtjens, K. Kobayashi et al., "Mammalian Cry1 and Cry2 are essential for maintenance of circadian rhythms," Nature, vol. 398, no. 6728, pp. 627-630, 1999.

[120] E. A. Van der Zee, R. Havekes, R. P. Barf et al., "Circadian time-place learning in mice depends on Cry genes," Current Biology, vol. 18, no. 11, pp. 844-848, 2008.

[121] C. Mulder, E. A. Van Der Zee, R. A. Hut, and M. P. Gerkema, "Time-place learning and memory persist in mice lacking functional Per1 and Per2 clock genes," Journal of Biological Rhythms, vol. 28, no. 6, pp. 367-379, 2013.

[122] J. P. Adams and J. D. Sweatt, "Molecular psychology: roles for the ERK MAP kinase cascade in memory," Annual Review of Pharmacology and Toxicology, vol. 42, no. 1, pp. 135-163, 2002.

[123] S. Peng, Y. Zhang, J. Zhang, H. Wang, and B. Ren, "ERK in learning and memory: a review of recent research," 
International Journal of Molecular Sciences, vol. 11, no. 1, pp. 222-232, 2010.

[124] G. Q. Butcher, H. Dziema, M. Collamore, P. W. Burgoon, and K. Obrietan, "The p42/44 mitogen-activated protein kinase pathway couples photic input to circadian clock entrainment," Journal of Biological Chemistry, vol. 277, no. 33, pp. 29519-29525, 2002.

[125] A. N. Coogan and H. D. Piggins, "Circadian and photic regulation of phosphorylation of ERK1/2 and Elk-1 in the suprachiasmatic nuclei of the Syrian hamster," The Journal of Neuroscience, vol. 23, no. 7, pp. 3085-3093, 2003.

[126] K. Obrietan, S. Impey, D. Smith, J. Athos, and D. R. Storm, "Circadian regulation of cAMP response elementmediated gene expression in the suprachiasmatic nuclei," Journal of Biological Chemistry, vol. 274, no. 25, pp. 1774817756, 1999.

[127] S. A. Tischkau, J. W. Mitchell, S.-H. Tyan, G. F. Buchanan, and M. U. Gillette, " $\mathrm{Ca}^{2+} / \mathrm{cAMP}$ response element-binding protein (CREB)-dependent activation of Per1 is required for light-induced signaling in the suprachiasmatic nucleus circadian clock," Journal of Biological Chemistry, vol. 278, no. 2, pp. 718-723, 2003.

[128] Z. Travnickova-Bendova, N. Cermakian, S. M. Reppert, and P. Sassone-Corsi, "Bimodal regulation of mPeriod promoters by CREB-dependent signaling and CLOCK/BMAL1 activity," Proceedings of the National Academy of Sciences, vol. 99, no. 11, pp. 7728-7733, 2002.

[129] K. Shimizu, T. Phan, I. M. Mansuy, and D. R. Storm, "Proteolytic degradation of SCOP in the hippocampus contributes to activation of MAP kinase and memory," Cell, vol. 128, no. 6, pp. 1219-1229, 2007.

[130] K. Shimizu, S. M. Mackenzie, and D. R. Storm, "SCOP/ PHLPP and its functional role in the brain," Molecular BioSystems, vol. 6, no. 1, pp. 38-43, 2010.

[131] Y. Romeo, X. Zhang, and P. P. Roux, "Regulation and function of the RSK family of protein kinases," Biochemical Journal, vol. 441, no. 2, pp. 553-569, 2012.

[132] A. Saraf, J. Luo, D. R. Morris, and D. R. Storm, "Phosphorylation of eukaryotic translation initiation factor $4 \mathrm{E}$ and eukaryotic translation initiation factor $4 \mathrm{E}$-binding protein (4EBP) and their upstream signaling components undergo diurnal oscillation in the mouse hippocampus: implications for memory persistence," The Journal of Biological Chemistry, vol. 289, no. 29, pp. 20129-20138, 2014.

[133] F. Hernández, J. Borrell, C. Guaza, J. Avila, and J. J. Lucas, "Spatial learning deficit in transgenic mice that conditionally over-express GSK-3 $\beta$ in the brain but do not form tau filaments," Journal of Neurochemistry, vol. 83, no. 6, pp. 1529-1533, 2002.

[134] M. Pardo, E. Abrial, R. S. Jope, and E. Beurel, "GSK3 $\beta$ isoform-selective regulation of depression, memory and hippocampal cell proliferation," Genes, Brain and Behavior, vol. 15, no. 3, pp. 348-355, 2016.

[135] S. Panda, M. P. Antoch, B. H. Miller et al., "Coordinated transcription of key pathways in the mouse by the circadian clock," Cell, vol. 109, no. 3, pp. 307-320, 2002.

[136] D. J. Durgan and M. E. Young, "The cardiomyocyte circadian clock: emerging roles in health and disease," Circulation Research, vol. 106, no. 4, pp. 647-658, 2010.

[137] S. Sahar, L. Zocchi, C. Kinoshita, E. Borrelli, and P. SassoneCorsi, "Regulation of BMAL1 protein stability and circadian function by GSK3 $\beta$-mediated phosphorylation," PLoS One, vol. 5, no. 1, article e8561, 2010.

[138] F. Dang, X. Sun, X. Ma et al., "Insulin post-transcriptionally modulates Bmall protein to affect the hepatic circadian clock," Nature Communications, vol. 7, 2016.

[139] Y. Liu, J. Sun, Y. Wang et al., "Deleting both PHLPP1 and CANP1 rescues impairments in long-term potentiation and learning in both single knockout mice," Learning \& Memory, vol. 23, no. 8, pp. 399-404, 2016.

[140] I. M. Mansuy, M. Mayford, B. Jacob, E. R. Kandel, and M. E. Bach, "Restricted and regulated overexpression reveals calcineurin as a key component in the transition from short-term to long-term memory," Cell, vol. 92, no. 1, pp. 39-49, 1998.

[141] H. Nakatsuka and K. Natsume, "Circadian rhythm modulates long-term potentiation induced at CA1 in rat hippocampal slices," Neuroscience Research, vol. 80, pp. 1-9, 2014.

[142] C. Barnes, B. McNaughton, G. Goddard, R. Douglas, and R. Adamec, "Circadian rhythm of synaptic excitability in rat and monkey central nervous system," Science, vol. 197, no. 4298, pp. 91-92, 1977.

[143] D. Chaudhury, L. M. Wang, and C. S. Colwell, "Circadian regulation of hippocampal long-term potentiation," Journal of Biological Rhythms, vol. 20, no. 3, pp. 225-236, 2005.

[144] K. M. Harris and T. J. Teyler, "Age differences in a circadian influence on hippocamapl LTP," Brain Research, vol. 261, no. 1, pp. 69-73, 1983.

[145] A. V. Raghavan, J. M. Horowitz, and C. A. Fuller, "Diurnal modulation of long-term potentiation in the hamster hippocampal slice," Brain Research, vol. 833, no. 2, pp. 311314, 1999.

[146] S. Peineau, C. Bradley, C. Taghibiglou et al., "The role of GSK-3 in synaptic plasticity," British Journal of Pharmacology, vol. 153, no. S1, pp. S428-S437, 2008.

[147] L.-L. Yuan, J. P. Adams, M. Swank, J. D. Sweatt, and D. Johnston, "Protein kinase modulation of dendritic $\mathrm{K}^{+}$ channels in hippocampus involves a mitogen-activated protein kinase pathway," The Journal of Neuroscience, vol. 22, no. 12, pp. 4860-4868, 2002.

[148] S. G. Birnbaum, "Structure and function of Kv4-family transient potassium channels," Physiological Reviews, vol. 84, no. 3, pp. 803-833, 2004.

[149] S. Impey, K. Obrietan, S. T. Wong et al., "Cross talk between ERK and PKA is required for $\mathrm{Ca}^{2+}$ stimulation of CREBdependent transcription and ERK nuclear translocation," Neuron, vol. 21, no. 4, pp. 869-883, 1998.

[150] V. Bodrikov, A. Pauschert, G. Kochlamazashvili, and C. A. O. Stuermer, "Reggie-1 and reggie-2 (flotillins) participate in Rab11a-dependent cargo trafficking, spine synapse formation and LTP-related AMPA receptor (GluA1) surface exposure in mouse hippocampal neurons," Experimental Neurology, vol. 289, pp. 31-45, 2017.

[151] J. J. Zhu, Y. Qin, M. Zhao, L. Van Aelst, and R. Malinow, "Ras and Rap control AMPA receptor trafficking during synaptic plasticity," Cell, vol. 110, no. 4, pp. 443-455, 2002.

[152] P. Chen, Z. Gu, W. Liu, and Z. Yan, "Glycogen synthase kinase 3 regulates $N$-methyl-D-aspartate receptor channel trafficking and function in cortical neurons," Molecular Pharmacology, vol. 72, no. 1, pp. 40-51, 2007.

[153] M. Ikeda, Y. Hojo, Y. Komatsuzaki et al., "Hippocampal spine changes across the sleep-wake cycle: corticosterone and 
kinases," Journal of Endocrinology, vol. 226, no. 2, pp. M13M27, 2015.

[154] A. Zeisel, A. B. Muñoz-Manchado, S. Codeluppi et al., "Cell types in the mouse cortex and hippocampus revealed by single-cell RNA-seq," Science, vol. 347, no. 6226, pp. 11381142, 2015.

[155] Y. Hayashi, S. Koyanagi, N. Kusunose et al., "The intrinsic microglial molecular clock controls synaptic strength via the circadian expression of cathepsin S," Scientific Reports, vol. 3, no. 1, p. 2744, 2013.

[156] M. Jasinska and E. Pyza, "Circadian plasticity of mammalian inhibitory interneurons," Neural Plasticity, vol. 2017, Article ID 6373412, 12 pages, 2017.

[157] G. P. Morris, I. A. Clark, R. Zinn, and B. Vissel, "Microglia: a new frontier for synaptic plasticity, learning and memory, and neurodegenerative disease research," Neurobiology of Learning and Memory, vol. 105, pp. 40-53, 2013.

[158] N. Ognjanovski, S. Schaeffer, J. Wu et al., "Parvalbuminexpressing interneurons coordinate hippocampal network dynamics required for memory consolidation," Nature Communications, vol. 8, article 15039, 2017.

[159] S. E. Lutz, Y. Zhao, M. Gulinello, S. C. Lee, C. S. Raine, and C. F. Brosnan, "Deletion of astrocyte connexins 43 and 30 leads to a dysmyelinating phenotype and hippocampal CA1 vacuolation," Journal of Neuroscience, vol. 29, no. 24, pp. 7743-7752, 2009.

[160] M. Brancaccio, A. P. Patton, J. E. Chesham, E. S. Maywood, and M. H. Hastings, "Astrocytes control circadian timekeeping in the suprachiasmatic nucleus via glutamatergic signaling," Neuron, vol. 93, no. 6, pp. 1420-1435.e5, 2017.

[161] C. F. Tso, T. Simon, A. C. Greenlaw, T. Puri, M. Mieda, and E. D. Herzog, "Astrocytes regulate daily rhythms in the suprachiasmatic nucleus and behavior," Current Biology, vol. 27, no. 7, pp. 1055-1061, 2017.

[162] L. de Vivo, M. Bellesi, W. Marshall et al., "Ultrastructural evidence for synaptic scaling across the wake/sleep cycle," Science, vol. 355, no. 6324, pp. 507-510, 2017.

[163] G. Tononi and C. Cirelli, "Sleep function and synaptic homeostasis," Sleep Medicine Reviews, vol. 10, no. 1, pp. 4962, 2006.

[164] L. Appelbaum, G. Wang, T. Yokogawa et al., "Circadian and homeostatic regulation of structural synaptic plasticity in hypocretin neurons," Neuron, vol. 68, no. 1, pp. 87-98, 2010.

[165] I. Elbaz, N. S. Foulkes, Y. Gothilf, and L. Appelbaum, "Circadian clocks, rhythmic synaptic plasticity and the sleep-wake cycle in zebrafish," Frontiers in Neural Circuits, vol. 7, p. 9, 2013.

[166] J. Q. M. Ly, G. Gaggioni, S. L. Chellappa et al., "Circadian regulation of human cortical excitability," Nature Communications, vol. 7, article 11828, 2016. 


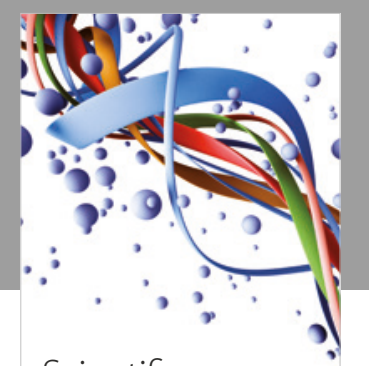

Scientifica
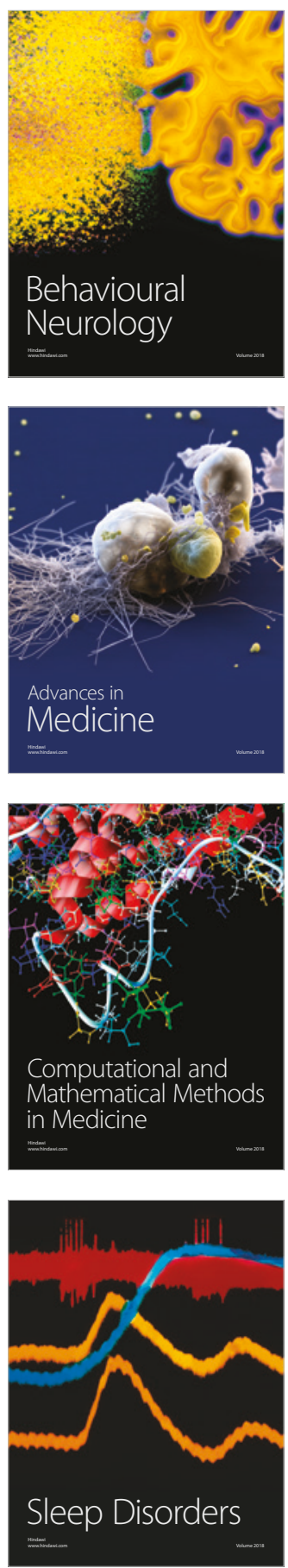

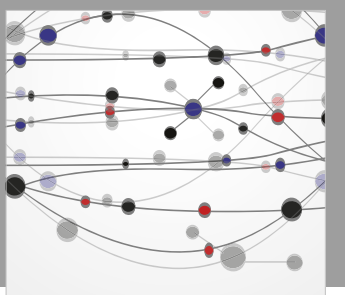

The Scientific World Journal

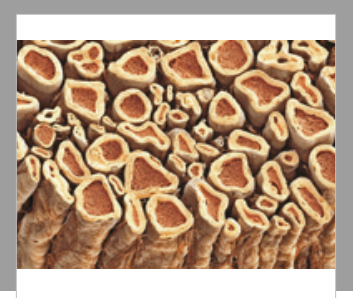

Case Reports in

Neurological Medicine

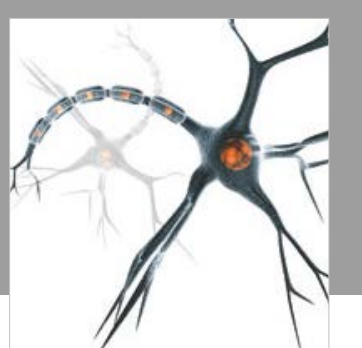

Neural Plasticity

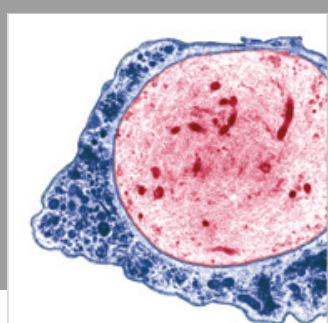

Multiple Sclerosis

International

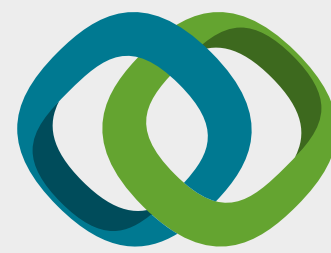

Hindawi

Submit your manuscripts at

www.hindawi.com
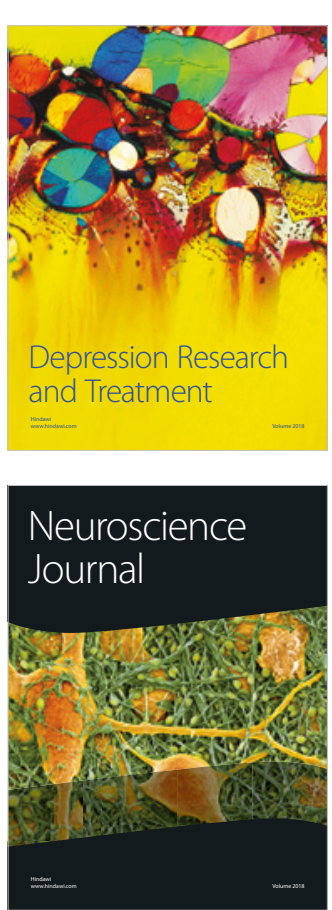

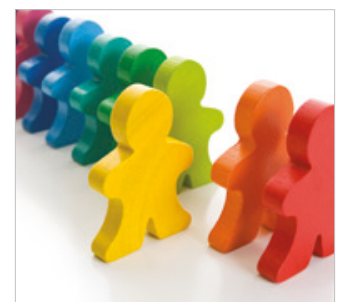

Autism

Research and Treatment
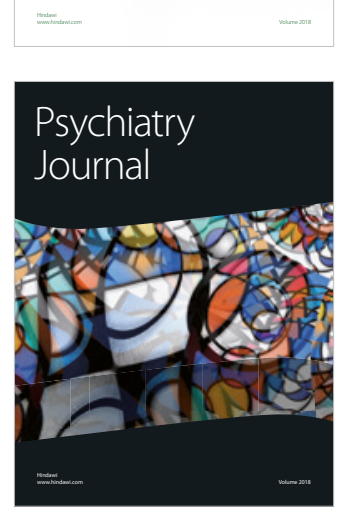
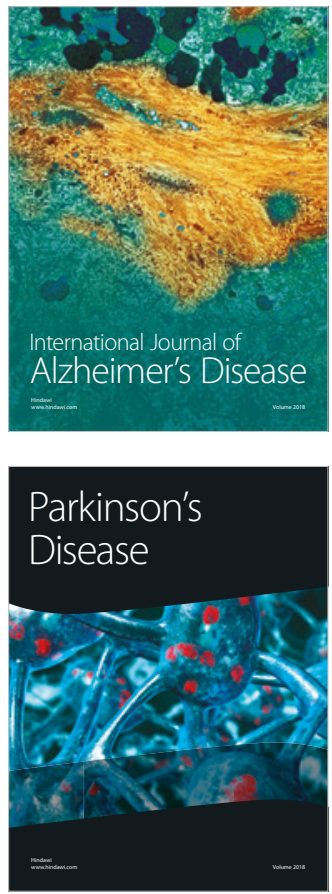
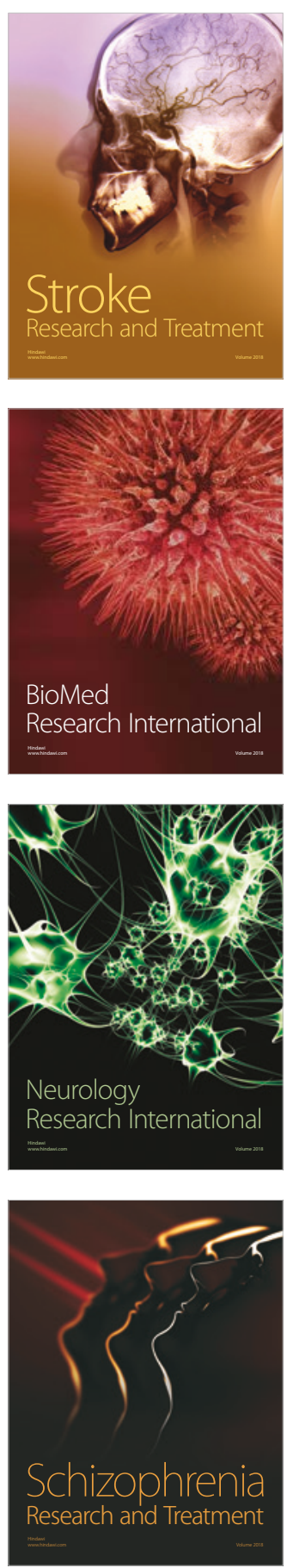